
$\$$ Research Square
Preprints are preliminary reports that have not undergone peer review.
They should not be considered conclusive, used to inform clinical practice, or referenced by the media as validated information.

\title{
Association of Complementary feeding practices and household food insecurity and anthropometric status of children aged 6-23 months old in Kabul city
}

\section{Gholam Reza Ahrar}

Ghazanfar Institute of Health and Science https://orcid.org/0000-0002-2952-7792

Leila Azadbakht ( $\square$ azadbakhtleila@gmail.com)

\section{Research}

Keywords: Complementary feeding, breast feeding, Food insecurity, anthropometric status, children 6-23 months, Afghanistan

Posted Date: July 1st, 2020

DOl: https://doi.org/10.21203/rs.3.rs-39189/v1

License: (c) (i) This work is licensed under a Creative Commons Attribution 4.0 International License. Read Full License 


\section{Abstract}

Introduction During the first 1000 days of a child life, appropriate infant feeding practices are fundamental to growth, health and development of a child. Globally only one in six children receive a minimum acceptable diet. In Afghanistan, the status of minimum meal frequency, dietary diversity and acceptable diet were $55 \%, 23 \%$ and $18 \%$, respectively among children aged $6-23$ months. This study designed with the aim of determines the association of complementary feeding (CF) indicators and household food insecurity and anthropometric status of Afghan children aged 6-23 months. Methods We were selected 300 children aged 6-23 months old in this cross-sectional study through simple method. Three 24 -hour dietary recall were collected for CF practices. Socioeconomic and United State Department of Agriculture (USDA) food security questionnaire were used from interview method and nutritional status was assessed using World Health Organization indicators. Chi-Square analysis were used to determined association between anthropometry of children among different age groups, complementary feeding indicators and household Food insecurity. Independent sample test was used to determined association between nutrient intake and complementary feeding indicators. Results Results showed that $59 \%$ of children received timely introduction of CF and Minimum Meal Frequency (MMF), Minimum Dietary Diversity (MDD) and Minimum Acceptable Diet were met by $87.7 \%$, $44.7 \%$ and $42.3 \%$, respectively. Prevalence rate of food insecurity was $90.7 \%$. Result for odds ratio and $95 \% \mathrm{Cl}$ showed there is association between (Length for Age Z-score (LAZ) with MMF), (Weight for Age Z-score (WAZ), Weight for Length Z-score (WLZ) and Length for Age Z-score (LAZ) with MDD and MAD). Result for odds ratio and $95 \% \mathrm{Cl}$ also showed there are significant associations between WAZ, WLZ and LAZ with household food insecurity. Conclusion Household food insecurity and weak complementary feeding make more prevalence of malnutrition.

\section{Introduction}

Really the first 1000 days of a child is 1000 golden days of her/his life or is a critical window to promote health and development and prevent stunting. Risk factors of children stunting may be insufficient quantities and inadequate quality of complementary foods, together with poor feeding practices and increased rates of infection during this period [1]. During the first 2 years of life, appropriate infant feeding practices are fundamental to growth, health and development of a child [2].

Globally only one in six children receive a minimum acceptable diet [3][5]. Similar to most developing countries, improper feeding practices remain a common problem in Afghanistan too. In Afghanistan the status of minimum meal frequency, dietary diversity and acceptable diet were $55 \%$, $23 \%$ and $18 \%$, respectively among children aged $6-23$ months [4]. WHO shows probability effect of feeding practices on nutritional status of children, about $32 \%$ of children under five were stunted and $10 \%$ were wasted due to poor breastfeeding and CF [5].

Household food insecurity is other important cause of malnutrition that has effect on vulnerable groups in societies, especially the poor women of reproductive age and children under the age of five as they are at high risk [6, 7]. It is one of nutritional status determinant among children especially in developing countries. Afghanistan is one of those countries that majority of its population is insecure [8, 9]. Seasonal Food Security Assessment in Afghanistan (SFSA) 2017 data shows that there are 30\% of the households are either on the borderline or are poor in terms of their food consumption scores. The SFSA finding and Afghanistan Living Conditions Survey 2014, showed 39\% of households are food insecure [10].

According to our knowledge, there is no study that shows association between recommended WHO Infant and young Child Feeding (IYCF) indicators with household food insecurity and anthropometric status in Kabul Afghanistan. Therefore, this study, designed to determine the association between of the CF practices and household food insecurity and anthropometric status of children 6-23 months in Kabul Afghanistan

\section{Research Design And Methods Study design, participants and sampling}

This community- based cross-sectional study was conducted for twelve months in 2019 in all central and governmental clinics and hospitals of Kabul and data were collected for 300 children aged 6-23 months. Participants were those children who were came for apply vaccination with aged of 9 and 15 months old in our plan but, we were added those children who were came with their mothers and were came for anthropometric measurement in to our study. The samples were selected by simply method with the following inclusion criteria: 1) Children aged 6-23 months, 2) the mothers who were agreed to interview, 3) the children who were apparently healthy, not experienced chronic/congenital diseases, such as heart abnormality and not having experienced acute conditions such as fever, diarrhea and respiratory infection in the two previous weeks.

For sampling, we were selected our samples according to population size of those regions or hospitals/health centers which covered them.

\section{Data collection}

For data collection first of all, we were collected information about nutrient intake, dietary diversity and meal frequency of children by using the 24-dietary recall from three days of a week and quantitative data, socioeconomic and demographic characteristics of children were collected using structured questionnaire in face to face interviews between mothers of children and interviewers. According to our objectives we were add 18-items USDA Food Security questionnaire at the end of general questionnaire too. We were included the following variables for a child: sex, age, birth order, birth interval, weight, recent vitamin A and iron supplementation status, vaccination record, and recent symptoms of diarrhea, fever and cough. For mothers we were included these variables: age, smoking status, use of reproductive health services: delivery at health facility, delivery with skilled birth assistance, 
caesarean delivery, number of antenatal care visits, timing of postnatal check-up for mother and for child, education level, occupation. For fathers, we were included age, education level, and occupation. For Household characteristics we were included: household head, household size, number of children under five, type of cooking fuel, water source, toilet conditions and sharing, and household wealth quintile and time to get to water source.

\section{Procedures}

The four main complementary feeding indicators are: timely introduction of CF, MMF, MDD and MAD which we were got required information about timely introduction of CF via question in the questionnaire and MMF, MDD and MAD via 24-hour dietary recalls of food and liquid consumption during the previous day of the survey [11]. We were compared these CF indicators with four anthropometric measurements which they were Mid Upper Arm Circumference (MUAC), Weight for Age Z-score (WAZ), Length for Age Z-score (LAZ) and Weight for Length Z-score (WLZ) and with household food security. For prevalence of MDD we were used 24-hour dietary recall result, We were categorized dietary diversity as met when the child consumed 4 out of the bellow 7 food groups: cereals and tubers, legumes, dairy products (milk, yoghurt, and cheese), flesh food (meat, fish, poultry, and organ meat), eggs, vitamin A-rich fruits and vegetables, and other fruits and vegetables $[12,13]$. We were got MMF information (frequency of meal and snack) through last 24-hour recall too. Recommended standard for infants who was only breastfeed, meal for children aged 6-8 months was 2 times/day or more, meal of children aged 9-23 months was 3 times/day or more and non-breastfeed children's meal was 4 times/day or more. MAD were good for those children aged 6-23 months who received the MDD and the MMF in the previous 24 hours (day or night). For breastfeed children, MAD were achieved if the child meets both the MMF and MDD criteria and for non-breastfeed children, the child was required to receive at least four food groups excluding dairy products, two milk feeds and MMF $[12,13]$. We were had some observation measuring like MUAC which were measured on the left arm, at the midpoint between the elbow and the shoulder. The arms were relaxed and hanging down the side of the body during measuring MUAC. A MUAC measuring tape were placed around the arm. The value was road from the window of the tape without pinching the arm or leaving the tape lose [14]. We were road value of MUAC tape and were categorized them as: $\geq 11.5$ severe acute malnutrition, $11.5<$ to $\geq 12.5$ moderate acute malnutrition and $>12.5$ were in normal range [ 15 ]. Body weight and length measurement were collected to determine the nutritional status of children, we were used Sec-a digital weight scale with a precision of $0.1 \mathrm{Kg}$ for measuring of body weight and for measuring of length, we were used an infant length board with a precision of $0.1 \mathrm{~cm}$. We were categorized nutritional status like this: underweight was defined as a weight for age z-score less than -2 standard Deviation (SD), wasting as weight for length z-score less than -2 SD and stunting as length for age less than -2 SD. This analysis was done with using WHO Anthro 2005 v.2.0.4 software [16].

\section{Data management and analyzed}

First of all, we were change amount of received foods to portion size and after that we were change portion size to gram. Secondly, we had data entry and were transferred food grams in to Nutritionist IV (a diet analysis module) version 3.5.2 for analysis. This program was changed food grams to nutrient intake with particular size. Collected data like quantitative data, socioeconomic and demographic characteristics of children and 18-items USDA food security were analyzed after editing, coding and entry. We were used IBM SPSS Statistics version 24 for analysis of this data. Crosstabs and Chi-Square analysis were used to determined association among anthropometric measurement of children with different age groups and different complementary feeding indicators. This analysis was used to determined association among household Food Security with complementary feeding indicators too. Independent sample test was used to determined association between nutrient intake and complementary feeding indicators. Logistic regression was used to determined association between anthropometric measurement of children with complementary feeding indicators and household food insecurity which output were presented as adjusted odds ratios (AOR) with 95\% confidence intervals (CI).

\section{Results}

\section{Sample characteristics}

Table 1 present demographic and socioeconomic characteristics of subjects. After analyzing data of this survey about half $49.3 \%$ of children age group were between $12-23$ months. More than half $54.3 \%$ of children were female. Less than half $38.3 \%$ of children were second to fourth births. More than half $62.3 \%$ of children had normal weight and $27.7 \%$ were low birth weight at birth. Birth interval of $27.3 \%$ of children were within a $24-\mathrm{months}$. More than twothird $92.3 \%$ of children had completed all the vaccinations scheduled for their age. More than half $56.7 \%$ of the mothers were aged $25-35$ years and just $2 \%$ of them were smoker. More than two-third $83 \%$ of mother were used reproductive health services, $89.7 \%$ of them were delivered at health facility, $90 \%$ of them delivered their children with assistance of a midwife or a doctor and $15 \%$ of them had caesarean delivery. Our result was showed $43 \%$ of mothers were used four or more antenatal check-up services and only $11.7 \%$ of them were used two or more postnatal check-up services and $39 \%$ of children were used two or more postnatal check-up services. Among these 300 samples $60 \%$ of mothers were illiterate and jobs of most of them 88.7 were housewife and more than tree-fourth $76.7 \%$ of them were not exposure to none of medias. Results were showed $29.3 \%$ of the father were aged $\geq 36$ years and $39.3 \%$ of them were illiterates and $29.3 \%$ of them were labor. Household head of $71.3 \%$ of participants were father. Mean of household size were 6.72 which $37 \%$ of them were $\geq 7$ persons in a household and mean of children under five were 1.59 which only $8 \%$ of household had $\geq 3$ children under five. Type of cooking fuel of $91.7 \%$ of household were LPG, $52.3 \%$ of household water source were shaft which, around half $48.3 \%$ of them were used from unimproved source of drinking water. Source of drinking water of $87.7 \%$ of them were in their own yard and 84.71 minutes were their mean of time to get water source. More than one-thirds $40.3 \%$ of the households did not have improved toilet facilities. More than half $59.0 \%$ of households were poor. 


\section{Association of household food security with complementary feeding indicators}

Result of table 3 showed there is no association between food security (secure and total insecure) with MMF $(P=0.139)$ and introduction of complementary feeding practices at six months $(P=0.846)$ but there are associations between food security with MDD $(P=0.003)$ and $M A D(P=0.004)$.

Table 4 showed the association of food security and insecurity with their sup groups (Food insecure without hunger, food insecure with moderate hunger and food insecure with severe hunger) among CF indicators. The results were the same as Table of 3 with different p-value. There is no association between household food security with MMF $(P=0.102)$ and timely introduction of $C F(P=0.198)$ but there are associations between household food security with $\operatorname{MDD}(P=0.0001)$ and $M A D(P=0.0001)$.

Result for odds ratios and 95\% confidence intervals for low MUAC, low WAZ, low WLZ and low LAZ among those who were food insecure are shown in Table 8. This Table showed there is no association between MUAC and household food insecurity [OR 2.49; $\mathrm{Cl}(0.32-19.20)$; $\mathrm{P}=0.380$ ], but there are significant associations between WAZ, WLZ and LAZ with household food insecurity [OR 3.66; $\mathrm{Cl}(1.44-9.32) ; \mathrm{P}=0.006$ ], [OR 4.83; $\mathrm{Cl}$ (1.96-36.25); $\mathrm{P}=$ 0.004], [OR 5.16; Cl (2.11-12.56); $\mathrm{P}=0.0001]$, respectively.

\section{CF practices of children aged 6-23 months}

Results for CF practices of children aged 6-23 months are shown in Fig. 2. This figure and Table 1 show $87.7 \%$ of children met MMF, $44.7 \%$ of children met MDD and MAD of $42.3 \%$ of them were good. When children met MMF and MDD and start complementary feeding at sixth month of their birth so they had appropriate complementary feeding, in this study $43.5 \%$ of children had appropriate complementary feeding. Results show $53.7 \%$ of children were breastfeed until 1 hour after birth, $72.3 \%$ of them had exclusive breast milk until the age of six months, $78 \%$ of them were stilled breastfeed until the age of two years old or more and $59 \%$ of them were started CF at beginning of sixth months. The results of study also showed only $8.3 \%$ of children were received Iron or multivitamin supplement and $11.3 \%$ of them were consumed of fortified food in the last three months. Food groups consumption were as follows: meat $\geq 3$ time/week $2.7 \%$, eggs $\geq 4$ time/week $4 \%$, fish $\geq 4$ time/week $0 \%$, legumes $\geq 3$ time/week $19.7 \%$, Vegetables $\geq 4$ time/week $13 \%$, fruits $\geq 3$ time/week $29.3 \%$ and dairy $\geq 3$ time/week $59.3 \%$ and $47.3 \%$ of children only were consumed milk powder.

\section{Association of Nutritional status with complementary feeding indicators}

Tables 5 and 6 show anthropometric measurement of children among different complementary feeding indicators. All anthropometric measurement of children in this study $\{$ MUAC $(P=0.003)$, WAZ $(P=0.001)$ and WLZ $(P=0.033)\}$ were associated with timely introduction of complementary feeding at six months, expect LAZ $(P=0.133)$. Apart from MUAC $(P=0.927)$, all anthropometric measurement of children $\{W A Z(P=0.0001), W L Z(P=0.001)$ and $L A Z$ $(P=0.0001)\}$ were associated with MMF. The MUAC were not associated with MDD $(P=0.334)$, but WAZ $(P=0.0001)$ and WLZ $(P=0.0001)$ were associated with MDD and also LAZ were not associated with MDD ( $P=0.106)$. In the end also MUAC were not associated with MAD ( $P=0.136)$, but WAZ $(P=0.0001)$ and WLZ $(P=0.0001)$ were associated and LAZ were not associated with MAD $(P=0.058)$ too.

Result for odds ratios and 95\% confidence intervals for low MUAC, low WAZ, low WLZ and low LAZ among those who did not meet the complementary feeding criteria are shown in Table 9. This Table shows there is no association between MUAC with MMF [OR 1.01; $\mathrm{Cl}(0.28-3.59) ; \mathrm{P}=0.979]$, WAZ with MMF [OR 1.98; $\mathrm{Cl}(0.98-4.03) ; \mathrm{P}=0.057$ ] and WLZ with MMF [OR 1.79; $\mathrm{Cl}(0.89-3.58) ; \mathrm{P}=0.099$ ] expect LAZ with MMF which had significant association [OR 2.73; $\mathrm{Cl}(1.20-6.20) ; \mathrm{P}=0.016$ ]. Odds ratios and $\mathrm{Cl}$ of anthropometric measurement with MDD which there is no association between MUAC and $\mathrm{MDD}$ [OR 1.38; $\mathrm{Cl}$ (0.58-3.25); $\mathrm{P}=0.463$ ] but there is association between WAZ, WLZ, LAZ and MDD [OR 2.78; $\mathrm{Cl}$ (1.73-4.46); $\mathrm{P}=0.0001]$, [OR 2.94; Cl (1.77-4.87); $\mathrm{P}=0.0001$ ] and [OR 1.74; $\mathrm{Cl}(1.09-2.78) ; \mathrm{P}=0.019]$, respectively. There is no association between MUAC and MAD too [OR 1.86; $\mathrm{Cl}(0.75-4.64) ; \mathrm{P}=0.179$ ] but there is association between WAZ, WLZ, LAZ and MAD [OR 3.12; Cl (1.93-5.05); $\mathrm{P}=0.0001]$, [OR 3.33; $\mathrm{Cl}(1.98-5.61) ; \mathrm{P}=0.0001$ ] and [OR 1.84; $\mathrm{Cl}(1.15-$ 2.94); $P=0.011$, respectively. We were not found association between MUAC [OR 0.25; $\mathrm{Cl}(0.10-0.64) ; P=0.004$ ], WAZ [OR 0.54; (0.34-0.87); $P=0.012$ ], WLZ [OR 0.48; (0.29-0.77); $P=0.003$ ] and LAZ [OR 0.76; $(0.47-1.23) ; P=0.270$ ] with timely introduction of complementary feeding.

\section{Nutrient intakes of children among different age categories}

Result of Table 2 shows, mean and SD of vitamin C intake among children aged 6-23m, 6-8m, 9-11m and 12-23m were 8.68 $\pm 9.21,9.62 \pm 14.00,8.36 \pm 7.51$ and $8.47 \pm 7.52 \mathrm{mg} / \mathrm{d}$, respectively. Mean and SD of vitamin B1 intake among children aged 6-23m, 6-8m, 9-11m and 12-23m were $0.31 \pm 0.20,0.22 \pm 0.22$, $0.26 \pm 0.16$ and $0.38 \pm 0.20 \mathrm{mg} / \mathrm{d}$, respectively. Mean and SD of vitamin B6 intake among children aged $6-23 \mathrm{~m}, 6-8 \mathrm{~m}, 9-11 \mathrm{~m}$ and $12-23 \mathrm{~m}$ were $0.22 \pm 0.15$, $0.13 \pm 0.10,0.21 \pm 0.12$ and $0.27 \pm 0.16 \mathrm{mg} / \mathrm{d}$, respectively. Mean and SD of vitamin B12 intake among children aged 6-23m, 6-8m, 9-11m and $12-23 \mathrm{~m}$ were $0.17 \pm 0.22,0.10 \pm 0.15,0.12 \pm 0.13$ and $0.23 \pm 0.27 \mathrm{Ug} / \mathrm{d}$, respectively. Mean and SD of calcium intake among children aged $6-23 \mathrm{~m}, 6-8 \mathrm{~m}, 9-11 \mathrm{~m}$ and $12-23 \mathrm{~m}$ were $114.40 \pm 109.42,102.24 \pm 138.13,91.17 \pm 88.58$ and $133.61 \pm 104.52 \mathrm{mg} / \mathrm{d}$, respectively. Mean and SD of Iron intake among children aged 6-23m, 6-8m, $9-11 \mathrm{~m}$ and $12-23 \mathrm{~m}$ were $2.29 \pm 1.68,1.74 \pm 1.98,1.99 \pm 1.26$ and $2.70 \pm 1.67 \mathrm{mg} / \mathrm{d}$, respectively. Mean and SD of Zinc intake among children aged 6-23m, 6$8 \mathrm{~m}, 9-11 \mathrm{~m}$ and $12-23 \mathrm{~m}$ were $0.87 \pm 0.60,0.44 \pm 0.33,0.71 \pm 0.44$ and $1.14 \pm 0.63 \mathrm{mg} / \mathrm{d}$, respectively.

Food group consumption by age of children

Page $4 / 21$ 
All food groups consumptions were calculated as time per week and they are: Mean and SD of red and chicken meat consumption among children aged $6-23 \mathrm{~m}, 6-8 \mathrm{~m}, 9-11 \mathrm{~m}$ and $12-23 \mathrm{~m}$ were $0.63 \pm 0.75,0.40 \pm 0.57,0.40 \pm 0.59$ and $0.87 \pm 0.84$, respectively. Mean and SD of Legumes consumption among children aged $6-23 \mathrm{~m}, 6-8 \mathrm{~m}, 9-11 \mathrm{~m}$ and $12-23 \mathrm{~m}$ were $1.69 \pm 1.41,0.58 \pm 0.75,1.47 \pm 1.20$ and $2.31 \pm 1.44$, respectively. Mean and SD of vegetables consumption among children aged $6-23 \mathrm{~m}, 6-8 \mathrm{~m}, 9-11 \mathrm{~m}$ and $12-23 \mathrm{~m}$ were $1.65 \pm 1.66,0.50 \pm 1.03,1.54 \pm 1.52$ and $2.20 \pm 1.70$, respectively. Mean and SD of Fruits consumption among children aged 6-23m, 6-8m, 9-11m and 12-23m were 2.07 $\pm 1.90,1.51 \pm 1.91$, $1.95 \pm 1.70$ and 2.37 \pm 1.97 , respectively. Mean and SD of Grains consumption among children aged 6-23m, 6-8m, 9-11m and 12-23m were 16.01 \pm 8.20, $11.53 \pm 6.38,15.80 \pm 8.32$ and 18.01 \pm 8.10 , respectively

\section{Conclusion}

As children have very fast growth in 6-23 months of their old, they need to having a good complementary feeding because complementary feeding period represents a window of opportunity for preventing all forms of malnutrition, including stunting, wasting, overweight and obesity. Our result found less than $50 \%$ of children are benefiting from MDD and MAD, beside this result showed very low consumption rate of fruits, vegetables and animal source foods. From other side most of the households live in food insecurity situation. Household food insecurity and weak complementary feeding make more prevalence of malnutrition. For prevent from these problems a long-term action plan is needed and should add these actions in to the plan: raising awareness and giving more nutrition education to mother, families, caregivers and health care worker, income generating activities to limit economic problems. Finally, we need to do more researches to have more accurate data or information that be comprehensive and covers the whole of Afghanistan on complementary feeding practices and its related factors.

\section{Discussion}

Results of odds ratios and 95\% confidence intervals of low MUAC, low WAZ, low WLZ and low LAZ among those who did not meet complementary feeding criteria are shown as below: Results of Table 9 showed there was no association between MUAC, WAZ and WLZ with MMF expect LAZ which had association with MMF. This means Compared children who meet MMF, children who not meet MMF, marginally significant more likely to have low weight for age and low weight for length and significantly more likely to have low length for age.

Odds ratios and $\mathrm{Cl}$ of (low MUAC, low WAZ, low WLZ and low LAZ) with MDD, which there is no association between MUAC and MDD but there is significant association between WAZ, WLZ, LAZ and MDD. This means Compared children who meet MDD, children who not meet MDD, significantly more likely to have low weight for age, low weight for length and low length for age. There is no association between MUAC and MAD too but there is association between WAZ, WLZ, LAZ and MAD which this means compared children who meet MAD, children who not meet MAD, significantly more likely to have low weight for age, low weight for length and low length for age. We were not found association between MUAC, WAZ, WLZ and LAZ with introduction of CF at six months old. This means there is no odds ratio for low MUAC, low WAZ, low WLZ and low LAZ because of children who not meet introduction of $\mathrm{CF}$ at six months old.

According to our finding from Table 5 and 6 expect regarding the variable intitled introduction of complementary feeding at six-month-old, none of CF indicators (MMF, MDD and MAD) associated with MUAC. MUAC is one of the methods for finding malnutrition children, which proper complementary feeding especially start CF at six months old of children may help to children for having good MUAC and prevent from malnutrition. So MUAC is very important and this part of study showed early or late start of complementary feeding may have effect on MUAC. Secondly all CF indicators (introduction of CF at six months old, MMF, MDD and MAD) associated with weight for age z-score (underweight) and all CF indicators associated with weight for length z-score (wasting) too. It is logical which infants need to extra feeding after a long time (after six month) so should start CF on that time and when infants grow after six months need to eat different foods frequently, so if a child start CF on time and receive MMF and MDD it is acceptable and would prevent from underweight and wasting. So, this part of study showed for having good WAZ and WLZ should meet all complementary feeding indicators. Expect MMF none of CF indicators (introduction of CF at six months old, MDD and MAD) associated with length for age z-score (stunting). Trend of children growth is very fast so they need to more energy for growing better. If a child be hungry and miss energy intake frequently, it would be suffered to chronic malnutrition (stunting). So, MMF is important for a child' growth and it would prevent from stunting.

In the study result of Udoh and Amodu, there was a significant association $(p<0.05)$ between introduction of CF at six months old with wasting, the MDD was significantly associated with underweight and similarly, MAD was significantly associated with underweight too. Also, this study showed significant association between stunting and MMF, MDD and MAD [17].

In Saaka et al. study (which conducted for explore the relationship between IYCF indicators and child growth indicators in rural northern Ghana) the main finding was that three of the WHO core IYCF indicators were not associated with mean length for age z-score expect timely initiation of CF at 6 months and this study did not show any association between MDD or MMF and stunting. All WHO core IYCF indicators (introduction of CF at six months old, MMF, MDD and MAD) were not associated with mean weight for height/length z-score. Saaka et al. study presented significant positive association between introduction of CF at six months old and higher height for age z-score [18] but our study showed there is no association between introduction of $\mathrm{CF}$ at six months old and length for age z-score (stunting). In Ahmad et al. study there was no association on indicators of CF, namely MMF, MDD, MAD and timely introduction to CF with wasting, underweight and stunting [17]. Kimiywe et al. found that CF practices were significantly correlated with nutritional status, particularly MDD [19]. Korir JK's study also found that low MAD significantly correlated with wasting [20]. So, we can say a child have appropriate complementary feeding when he/she was breastfeeding at the time of study, met minimum meal frequency in the past 24 hours, met minimum dietary diversity in the past 24 hour and complementary feeding were introduced at six-month-old. As we discussed before most of previous

Page 5/21 
studies found association between anthropometric measurements of children with complementary feeding indicators expect Ahmad et al' study which found no association between anthropometric measurement of children with complementary feeding indicators. Like most studies, the result of this study confirmed most of hypotheses and found associations between anthropometric measurement and complementary feeding indicators. But we need to more studies for confirm these associations like systematic review or meta analyze.

Result for odds ratios and 95\% confidence intervals for low MUAC, low WAZ, low WLZ and low LAZ among food insecure subjects are shown in Table 8. This Table shows there is no association between MUAC and household food insecurity, but there is significant association between WAZ, WLZ and LAZ with household food insecurity. This means compared children who were food secure, children who were not food secure, significantly more likely to have low Weight for age, low weight for length and low length for age.

Result of Table 3 is shown association of household food security with complementary feeding indicators with $p$ value. This result showed there was no association between food security (secure and total insecure) and MMF, but there are associations between food security and MDD and food security and MAD. There is no association between food security and introduction of CF at six months old too. This means better household food security help children for having better MDD and MAD. Table of 4 is shown association of food security and insecurity with their sup groups (Food insecure without hunger, food insecure with moderate hunger and food insecure with severe hunger) among CF indicators. This Table also had the same result with Table of 3 with different p-value. There is no association between household food security (secure and insecure with their subgroups) and MMF, but there are associations between household food security (secure and insecure with their subgroups) and MDD and food security (secure and insecure with their subgroups) and MAD and also there is no association between food security (secure and insecure with their subgroups) and introduction of CF at six months old. The findings confirm that most of Kabul households live in insecurity situation as only $9.3 \%$ of the households in the study were food secure. Low level of household food secure may be because of bias: In Afghanistan some health services providers or NGOs had some services to malnutrition mother/children like giving malnutrition materials (RUTF, RUSF, sprinkle powder, grains and etc.) to malnutrition child/mother they thought food security questionnaires are belong to these materials and from other side when we had interview about food security questionnaire, some of them asked: You asked me these questions for financial or material helping? Or after this questionnaire you would give malnutrition material to me or my child? After asking these questions by two or three persons, to solve this problem, I first explained to them that this questionnaire was not for any financial or material help, this is just a research for finding nutrition or complementary feeding problems of Kabul children.

Our study result showed there is no association between food insecurity and MMF and introduction of CF at six months old, but showed association between household food insecurity and MDD and MAD. We categorized MDD as met when children consumed 4 groups out of 7 food groups and MAD were good when children met both MMF and MDD. A child for having a good growth and prevent from underweight, wasting and stunting should follow CF practices guideline. So those children who live in food insecurity situation cannot receive MDD or MAD and risk of malnutrition is more between these children. Macharia et al. study showed similar result: infants living in food secure household were significantly more likely to achieve appropriate infant feeding practices than those in food insecure household. Infants living in food secure household were significantly associate with introduction of CF at six months old, MDD and MAD which compared with infants from food insecure household without MMF [21]. Two other studies conducted in rural Bangladesh reported similar finding. Saha et al. study showed better household food security status was associated with better infant feeding practices for children aged 6-12 months [22] and Owais et al. showed that the odds of receiving a minimally acceptable diet for infants in most food secure households was higher than for infants living in least food secure households [23].

Result of Table 2 showed receive of all nutrients and food groups were sub optimal and lower than recommended amount which can have different reasons. In our study were many children who were completed their six months old or may more, but were did not start complementary feeding and receive of their nutrients and food groups from way of diet were zero which these zeros had effect on total mean and SD of nutrient and food intake which this can be one of those reasons. The fruits of Afghanistan are seasonal, Fruits are cheap and more in their seasons and most of people can use from, but after end of their seasons fruits come from other countries which they are less and expensive because Afghanistan don't have especial refrigerator for saving seasonal fruits, So because of that most of people can't sue enough fruits and this study were done in season which fruits were less. This can be another reason for low level of nutrient and fruit intake. There is a high rate of illiteracy, poverty and food insecurity in the country which can affect people's nutrient and food intake. Finally, there is no previously study which explored complementary feeding practices and dietary intake of infants and children aged 6-23 months within the Afghanistan so, we need to do more researches to focus on nutrient intakes and its relationship with complementary feeding indicators and other variables.

According to definition of complementary feeding indicators our result showed that all CF indicators (MDD, MAD, introduction of CF at start of sixth month, consumption of Iron or multivitamin supplementation and fortified feeding) in this study were sub-optimal and still low , without MMF and Exclusive Breast Feeding (EBF) which they are better than other but they are not completely good. Prevalence of complementary feeding practices in this study was similar with a study conducted by Ahmad et al. in Aceh, Indonesia. Result of Ahmad et al' study was showed that $39 \%$ of children were exclusively breastfed, only $61 \%$ received prolonged breastfeeding and $50 \%$ received timely introduction CF. MMF, MDD and MAD were met by $74 \%, 50 \%$ and $40 \%$ of the children, respectively [17]. In a previous study from Muzi Na and et al. in Afghanistan which conducted for predictors of CF practices and were used from analysis of the 2015 demographic and health survey data, the prevalence of introduction of CF at six months old between 6-8m aged, MMF, MDD and MAD among children 6-8 months were $56 \%, 55 \%, 23 \%$ and $18 \%$, respectively [4]. Our study result showed better situation in part of CF indicators than study of Muzi $\mathrm{Na}$ and et al, surely this is result of health services and giving health education to people as we can see in community. Globally, $64.5 \%$ of infants 6-8 months of age were received introduction of CF at six months old on 2017, and global rates of MMF, MDD and MAD were low at $50.3 \%, 28.2$, and $15.9 \%$ respectively [1]. The present study finding was also higher than global and that reported by WHO found that less than onefourth of the children aged 6-23 months in developing countries had good consumption quality [24] but they still remained under the optimal level. I

Page 6/21 
should add, our study was designed in capital of Afghanistan which most of Kabul people may have better economic situation, better accessibility to health services and may have higher education level than people of other provinces and from other side our sample size was very small. So, these four reasons or perhaps more, may show high level of CF indicators in all Afghanistan.

\section{Limitations}

Low rate cooperation of mothers for face to face interview was one of our limitation and for solving and decreasing it we were said to mothers which we would learn those mothers who have good cooperation, about proper children complementary feeding.

We were had a female interviewer because of Afghanistan culture which some of mothers didn't present for having interview with a male interviewer.

Most of the mothers were illiterate and data collection was done by interview method.

Start and opening late of Health facility or hospitals and early end and closing (daily limitation of time) which we called many times to responsible but we can't solve this problem and because of this problem data collection were completed late.

Small sample size and just limited to Kabul city

\section{Symbols And Abbreviations}

AFDHS: Afghanistan Demographic and Health survey

ANC: Ante Natal Care

AOR: Adjusted Odds Ratio

BMI: Body Mass Index

CF: Complementary Feeding

Cl: Confidence Interval

Cm: Centimeter

EBF: Exclusive Breast Feeding

et al: et alia: and others

Etc.: et Cetera

FI: Food Insecurity

g/d: Gram per Day

IBM: International Business Machines Corporation

Intro: Introduction of Complementary Feeding at six months

IYCF: Infant and Young Child Feeding

Kcal: Kilo Calorie

Kg: Kilo gram

LAZ: Length for Age Z-score

LPG: Liquefied Petroleum Gaz

M: month

MAD: Minimum Acceptable Diet

MAM: Moderate Acute Malnutrition

MDD: Minimum Dietary Diversity

Mg/d: Milligram per Day 
Min: Minute

MMF: Minimum Meal Frequency

MUAC: Mid Upper Arm Circumference

NFHS: National Family Health Survey

NGO: Non-governmental Organization

Open Epi: A Web-based Epidemiologic and Statistical Calculator for Public Health

OR: Odds Ratio

PPS: Probability Proportionate to Size

$\mathrm{RE} / \mathrm{d}$ : Retinol Requirement per day

RUSF: Ready to Use Supplementary Food

RUTF: Ready to Use Therapeutic Food

SAM: Severe Acute Malnutrition

SD: Standard Division

SFSA: Seasonal Food Security Assessment

SPSS: Statistical Package for the Social Sciences

TDHS: Tanzania Demographic and Health Survey

Ug/d: Micro gram per Day

UNICEF MIC: United Nations International Children's Emergency Fund - Multiple Indicator Cluster Surveys

USDA: United States Department of Agriculture

v.2.0.4: Version 2.0 .4

WAZ: Weight for Age Z-score

WHO: World Health Organization

WLZ: Weight for Length Z-score

\section{Declarations}

\section{- Ethics approval and consent to participate}

This research was done with this ethic code: (IR.TUMS.VCR.REC.1398.578) and the name of ethics committee was (Ethics committee in Research of Vice Chancellor for Research and Technology, Tehran University of Medical Sciences).

\section{- Consent for publication}

Not Applicable

\section{- Availability of data and materials}

Not Applicable

\section{- Competing interests}

The authors declare that they have no competing interests

\section{- Funding}

Source of funding was nutrition department of EU which had a capacity building project to Ministry of Public Health of Afghanistan. 


\section{- Authors' contributions}

Research was done by Gholam Reza Ahrar and Leila Azadbakht was as advisor professor.

\section{- Acknowledgements}

I would like to express my sincere gratitude to my advisor Prof. Leila Azadbakht for the continuous support about my research, for her patience, motivation, enthusiasm, and immense knowledge. Her guidance helped me in all the time of research and writing of this article.

\section{References}

1. White, J.M., et al., Complementary feeding practices: Current global and regional estimates. Maternal \& child nutrition, $2017.13:$ p. e12505.

2. Mitchodigni, I.M., et al., Complementary feeding practices of children aged 6-23 months in rural area, Southern-Benin: challenges and opportunities. 2017.

3. Berhanu, Z., T. Alemu, and D. Argaw, Predictors of inappropriate complementary feeding practice among children aged 6 to 23 months in Wonago District, South Ethiopia, 2017; case control study. BMC pediatrics, 2019. 19(1): p. 146.

4. Na, M., et al., Predictors of complementary feeding practices in Afghanistan: Analysis of the 2015 Demographic and Health Survey. Maternal \& child nutrition, 2018. 14: p. e12696.

5. Organization, W.H., World Health Organization Sixty-sixth World Health Assembly. 2013. 2013.

6. Bhattacharya, J., J. Currie, and S. Haider, Poverty, food insecurity, and nutritional outcomes in children and adults. Journal of health economics, 2004. 23(4): p. 839-862.

7. Black, R.E., et al., Maternal and child undernutrition and overweight in low-income and middle-income countries. The lancet, 2013. 382(9890): p. 427451.

8. Saaka, M. and S.M. Osman, Does household food insecurity affect the nutritional status of preschool children aged 6-36 months? International Journal of Population Research, 2013. 2013.

9. Kuku, O., C. Gundersen, and S. Garasky, Differences in food insecurity between adults and children in Zimbabwe. Food Policy, 2011. 36(2): p. 311-317.

10. Afghanistan Food Security Cluster Strengthening Humanitarian Response, SEASONAL FOOD SECURITY ASSESSMENT (SFSA) AFGHANISTAN, Government Media \& Information Center (GMIC). 2017.

11. WHO, U., A. USAID, and U. AED, Indicators for assessing infant and young child feeding practices. Geneva: World Health Organization, 2008.

12. World Health Organization, Infant and young child feeding: model chapter for textbooks for medical students and allied health professionals. 2009: World Health Organization.

13. Marías, Y. and P. Glasauer, Guidelines for assessing nutrition-related knowledge, attitudes and practices. 2014: Food and Agriculture Organization of the United Nations (FAO).

14. Motbainor, A., A. Worku, and A. Kumie, Stunting is associated with food diversity while wasting with food insecurity among underfive children in East and West Gojjam Zones of Amhara Region, Ethiopia. PloS one, 2015. 10(8): p. e0133542.

15. Standard operational procedure of public health nutrition. Afghanistan National Nutrition survey, Public Nutrition Department. Ministry of Public Health. 2013.

16. World Food Programme, Measuring and interpreting malnutrition and mortality. 2005, Energylink Roma.

17. Ahmad, A., et al., Complementary feeding practices and nutritional status of children 6-23 months old: formative study in Aceh, Indonesia. Nutrition Research and Practice, 2018. 12(6): p. 512-520.

18. Saaka, M., et al., How well do WHO complementary feeding indicators relate to nutritional status of children aged 6-23 months in rural Northern Ghana? BMC public health, 2015. 15(1): p. 1157.

19. Kimiywe, J. and P. Chege, Complementary feeding practices and nutritional status of children 6-23 months in Kitui County, Kenya. Journal of Applied Biosciences, 2015. 85: p. 7881-7890-7881-7890.

20. Korir, J.K., Determinants of complementary feeding practices and nutritional status of children 6-23 months old in Korogocho slum, Nairobi County, Kenya. Nairobi: Kenyatta University, 2013.

21. Macharia, T., et al., Association between household food security and infant feeding practices in urban informal settlements in Nairobi, Kenya. Journal of developmental origins of health and disease, 2018. 9(1): p. 20-29.

22. Saha, K.K., et al., Household food security is associated with infant feeding practices in rural Bangladesh. The Journal of nutrition, 2008. 138(7): p. 1383-1390.

23. Owais, A., et al., Household food security and infant feeding practices in rural Bangladesh. Public health nutrition, 2016. 19(10): p. 1875-1881.

24. World Health Organization. Infant and young child feeding [Internet]. Geneva: World Health Organization; [cited 2018 January 16]. Available from: http://www.who.int/news-room/fact-sheets/detail/infant-and-young-child-feeding.

\section{Tables}


Table 1: Socioeconomic and demographic characteristics among children in Kabul Afghanistan

\begin{tabular}{|c|c|}
\hline Child characteristics & Percent or mean (SD) $\mathrm{N}=300$ \\
\hline \multicolumn{2}{|l|}{ MMF } \\
\hline Met & 263(87.7) \\
\hline Not Met & $37(12.3)$ \\
\hline \multicolumn{2}{|l|}{ MDD } \\
\hline Met & $134(44.7)$ \\
\hline Not Met & $166(55.3)$ \\
\hline \multicolumn{2}{|l|}{ MAD } \\
\hline Met & $127(42.3)$ \\
\hline Not Met & $173(57.7)$ \\
\hline Appropriate complementary feeding & $77(43.5)$ \\
\hline Weight (kg) & $8.34 \pm 1.35$ \\
\hline 6-8 (months) & $7.02 \pm 0.82$ \\
\hline 9-11 (months) & $7.78 \pm 0.84$ \\
\hline 12-23 (months) & $9.24 \pm 1.10$ \\
\hline Height (cm) & $72.62 \pm 7.37$ \\
\hline \multicolumn{2}{|l|}{ MUAC (cm) } \\
\hline$(12.5<)$ normal & $276(92.0)$ \\
\hline (11.5 to $\geq 12.5)$ MAM & $23(7.7)$ \\
\hline$(\geq 11.5)$ SAM & $1(0.3)$ \\
\hline \multicolumn{2}{|l|}{ WAZ (SD) } \\
\hline $\operatorname{good}(-1<,<1 \mathrm{SD})$ & $158(52.7)$ \\
\hline partly normal $(-2<,<1)$ & 106(35.3) \\
\hline Underweight (<-2 SD) & $30(10.0)$ \\
\hline Severe underweight $(<-3$ SD) & $6(2.0)$ \\
\hline \multicolumn{2}{|l|}{ WLZ } \\
\hline $\operatorname{good}(-1<,<1 \mathrm{SD})$ & 191(63.7) \\
\hline partly normal $(-2<,<1 \mathrm{SD})$ & $85(28.3)$ \\
\hline Wasting $(<-2$ SD) & $15(5.0)$ \\
\hline Severe wasting $(<-3 \mathrm{SD})$ & $6(2.0)$ \\
\hline Other & $3(1.0)$ \\
\hline \multicolumn{2}{|l|}{ LAZ } \\
\hline $\operatorname{good}(-1<,<1 \mathrm{SD})$ & $121(40.3)$ \\
\hline partly normal $(-2<,<1 \mathrm{SD})$ & 107(35.7) \\
\hline Stunting $(<-2$ SD) & $55(18.3)$ \\
\hline Severe stunting $(<-3 \mathrm{SD})$ & $13(4.3)$ \\
\hline Other & $4(1.3)$ \\
\hline \multicolumn{2}{|l|}{ Breastfed until 1 hour after birth } \\
\hline Yes & $161(53.7)$ \\
\hline No & $138(46.0)$ \\
\hline Don't Know & $1(0.3)$ \\
\hline \multicolumn{2}{|c|}{ Exclusive breast milk until the age of 6 months } \\
\hline Yes & $217(72.3)$ \\
\hline
\end{tabular}

Page $10 / 21$ 


\begin{tabular}{|c|c|}
\hline No & $83(27.7)$ \\
\hline \multicolumn{2}{|l|}{ Still breastfed } \\
\hline Yes & 234(78.0) \\
\hline No & $65(21.7)$ \\
\hline Don't Know & $1(0.3)$ \\
\hline \multicolumn{2}{|l|}{ Time of introducing CF } \\
\hline$<6$ months & 107(35.7) \\
\hline Start at 6 months & $177(59.0)$ \\
\hline Don't know & $6(2.0)$ \\
\hline After 6 months & $9(3.0)$ \\
\hline Unanswered & $1(0.3)$ \\
\hline \multicolumn{2}{|l|}{ Received of Iron or multivitamin supplement } \\
\hline Yes & $25(8.3)$ \\
\hline No & 273(91.0) \\
\hline Don't Know & $2(0.7)$ \\
\hline \multicolumn{2}{|l|}{ Consumed of fortified food in the last 3 months } \\
\hline Yes & $34(11.3)$ \\
\hline No & 263(87.7) \\
\hline Don't Know & $3(1.0)$ \\
\hline Frequency of red and chicken meat consumption (time/week) & $0.63 \pm 0.75$ \\
\hline Frequency of eggs consumption (time/week) & $1.00 \pm 1.32$ \\
\hline Frequency of fish consumption (time/week) & $0.02 \pm 0.18$ \\
\hline Frequency of legumes consumption (time/week) & $1.69 \pm 1.41$ \\
\hline Frequency of green leafy and orange vegetable consumption (time/week) & $1.65 \pm 1.66$ \\
\hline Frequency of fruits consumption (time/week) & $2.07 \pm 1.90$ \\
\hline Frequency of Grains consumption (time/week) & $16.01 \pm 8.20$ \\
\hline Frequency of Dairy consumption (time/week) & $7.85 \pm 10.16$ \\
\hline Frequency of Oils consumption (time/week) & $7.10 \pm 4.45$ \\
\hline Frequency of Sugar consumption (time/week) & $6.29 \pm 4.59$ \\
\hline Frequency of Milk Powder consumption (time/week) & $5.78 \pm 10.06$ \\
\hline Age of child (in month) & $12.54 \pm 5.00$ \\
\hline 6-8 (months) & $62(20.7)$ \\
\hline 9-11 (months) & $90(30.0)$ \\
\hline $12-23$ (months) & $148(49.3)$ \\
\hline \multicolumn{2}{|l|}{ sex of child } \\
\hline male & $137(45.7)$ \\
\hline female & $163(54.3)$ \\
\hline \multicolumn{2}{|l|}{ child birth order } \\
\hline 1 to 2 & $115(38.3)$ \\
\hline 3 to 4 & $99(33.0)$ \\
\hline$\geq 5$ & $86(28.7)$ \\
\hline \multicolumn{2}{|l|}{ Child birth weight status } \\
\hline low birth weight & $83(27.7)$ \\
\hline over weight & $17(5.7)$ \\
\hline
\end{tabular}

Page $11 / 21$ 


\begin{tabular}{|c|c|}
\hline Normal & $187(62.3)$ \\
\hline don't know & $13(4.3)$ \\
\hline \multicolumn{2}{|l|}{ Child birth interval } \\
\hline No Previous child & $65(21.7)$ \\
\hline previous birth $<24$ month & $82(27.3)$ \\
\hline$\geq 24$ month & $153(51.0)$ \\
\hline \multicolumn{2}{|l|}{ Complete vaccination of child } \\
\hline Complete & $277(92.3)$ \\
\hline Incomplete & $16(5.3)$ \\
\hline Not at all & $7(2.3)$ \\
\hline Fever in the last 2 weeks & $300(100)$ \\
\hline Diarrhea in the last 2 weeks & $300(100)$ \\
\hline Acute respiratory infection in the last 2 weeks & $300(100)$ \\
\hline \multicolumn{2}{|l|}{ Maternal Characteristic } \\
\hline Age of mother (Year) & $29.17 \pm 5.09$ \\
\hline \multicolumn{2}{|l|}{ Smoking status of mother } \\
\hline Smoker & $6(2.0)$ \\
\hline No Smoker & 294(98.0) \\
\hline \multicolumn{2}{|l|}{ Use reproductive health services } \\
\hline Yes & $249(83.0)$ \\
\hline No & $49(16.3)$ \\
\hline Don't Know & $1(0.3)$ \\
\hline Unanswered & $1(0.3)$ \\
\hline \multicolumn{2}{|l|}{ Delivered at health facility } \\
\hline Yes & $269(89.7)$ \\
\hline No & $31(10.3)$ \\
\hline \multicolumn{2}{|l|}{ Type of delivery assistance } \\
\hline Health professional & $270(90.0)$ \\
\hline Traditional birth attendant & $25(8.3)$ \\
\hline Other & $4(1.3)$ \\
\hline Unanswered & $1(0.3)$ \\
\hline \multicolumn{2}{|l|}{ caesarean delivery } \\
\hline Yes & $45(15.0)$ \\
\hline No & $250(83.3)$ \\
\hline Don't Know & $5(1.7)$ \\
\hline \multicolumn{2}{|l|}{ antenatal care visit of mother } \\
\hline None & $63(21.0)$ \\
\hline $1-3$ & 100(33.3) \\
\hline$\geq 4$ & $129(43.0)$ \\
\hline Don't know & $7(2.3)$ \\
\hline Unanswered & $1(0.3)$ \\
\hline \multicolumn{2}{|l|}{ postnatal check-up of mother } \\
\hline $0-1 d$ & $250(83.3)$ \\
\hline$>=2 d$ & $35(11.7)$ \\
\hline
\end{tabular}

Page 12/21 


\begin{tabular}{|c|c|}
\hline Missing & $5(1.7)$ \\
\hline Don't know & $7(2.3)$ \\
\hline Unanswered & $3(1.0)$ \\
\hline \multicolumn{2}{|l|}{ postnatal check-up for child } \\
\hline $0-1 d$ & $170(56.7)$ \\
\hline$>=2 d$ & 118(39.3) \\
\hline Missing & $4(1.3)$ \\
\hline Don't know & $2(0.7)$ \\
\hline Unanswered & $6(2.0)$ \\
\hline \multicolumn{2}{|l|}{ Mother education } \\
\hline Illiterate & $180(60.0)$ \\
\hline Elementary school & $37(12.3)$ \\
\hline Junior high school & 31(10.3) \\
\hline Senior high school (Diploma) & $19(6.3)$ \\
\hline Undergraduate & $14(4.7)$ \\
\hline Bachelor's degree & $16(5.3)$ \\
\hline Master's degree & $1(0.3)$ \\
\hline Don't know & $1(0.3)$ \\
\hline Unanswered & $1(0.3)$ \\
\hline \multicolumn{2}{|l|}{ mother exposure to media } \\
\hline Reading newspaper & $6(2.0)$ \\
\hline Listening to radio & $4(1.3)$ \\
\hline Watching TV & $44(14.7)$ \\
\hline social media & $12(4.0)$ \\
\hline None of them & $230(76.7)$ \\
\hline Don't know & $4(1.3)$ \\
\hline \multicolumn{2}{|l|}{ Employment status } \\
\hline housewife & 266(88.7) \\
\hline labor & $1(0.3)$ \\
\hline service & $3(1.0)$ \\
\hline Office employee & $12(4.0)$ \\
\hline Management and Staff & $4(1.3)$ \\
\hline Freelance & $11(3.7)$ \\
\hline Teacher & $2(0.7)$ \\
\hline Unanswered & $1(0.3)$ \\
\hline \multicolumn{2}{|l|}{ Paternal Characteristic } \\
\hline Age of father (Year) & $33.75 \pm 6.15$ \\
\hline \multicolumn{2}{|l|}{ Father education } \\
\hline Illiterate & 118(39.3) \\
\hline Elementary school & $20(6.7)$ \\
\hline Junior high school & $48(16.0)$ \\
\hline Senior high school (Diploma) & $44(14.7)$ \\
\hline Undergraduate & $17(5.7)$ \\
\hline Bachelor's degree & $51(17.0)$ \\
\hline
\end{tabular}

Page 13/21 


\begin{tabular}{|c|c|}
\hline Master's degree & $2(0.7)$ \\
\hline \multicolumn{2}{|l|}{ Employment status of father } \\
\hline Unemployed & $18(6.0)$ \\
\hline labor & $88(29.3)$ \\
\hline Farmer & $1(0.3)$ \\
\hline service & $22(7.3)$ \\
\hline Driver & $40(13.3)$ \\
\hline Office employee & $47(15.7)$ \\
\hline Management and Staff & $17(5.7)$ \\
\hline Freelance & 59(19.7) \\
\hline Military Officer & $4(1.3)$ \\
\hline Unanswered & $4(1.3)$ \\
\hline \multicolumn{2}{|l|}{ Household Characteristic } \\
\hline \multicolumn{2}{|l|}{ Household head } \\
\hline Father & 214(71.3) \\
\hline mother & 40(13.3) \\
\hline Father of Father & $27(9.0)$ \\
\hline Mother of Father & $7(2.3)$ \\
\hline Other & $10(3.3)$ \\
\hline Unanswered & $2(0.7)$ \\
\hline Household size & $6.72 \pm 4.33$ \\
\hline Number of children under five & $1.59 \pm 0.87$ \\
\hline \multicolumn{2}{|l|}{ Type of cooking fuel } \\
\hline Electricity & $5(1.7)$ \\
\hline LPG & $275(91.7)$ \\
\hline natural gas & $9(3.0)$ \\
\hline Wood & $7(2.3)$ \\
\hline straw/shrubs/grass & $4(1.3)$ \\
\hline \multicolumn{2}{|l|}{ Water source } \\
\hline Shaft & $157(52.3)$ \\
\hline Stave of City & $143(47.7)$ \\
\hline \multicolumn{2}{|c|}{ Unimproved source of drinking water } \\
\hline Yes & $145(48.3)$ \\
\hline No & $152(50.7)$ \\
\hline Unanswered & $3(1.0)$ \\
\hline \multicolumn{2}{|l|}{ source of water in own yard } \\
\hline Yes & $263(87.7)$ \\
\hline No & $37(12.3)$ \\
\hline Time to get to water source [15] & $84.71 \pm 37.88$ \\
\hline \multicolumn{2}{|l|}{ unimproved toilet } \\
\hline Yes & $121(40.3)$ \\
\hline No & $179(59.7)$ \\
\hline \multicolumn{2}{|l|}{ Shared toilet with other households } \\
\hline Yes & $149(49.7)$ \\
\hline
\end{tabular}

Page 14/21 


\begin{tabular}{|l|l|} 
No & $151(50.3)$ \\
Pousehold wealth & $177(59.0)$ \\
Middle & $108(36.0)$ \\
Riche & $15(5.0)$ \\
\hline Zone & \\
The 1st zones & $23(7.7)$ \\
The 2nd zones & $19(6.3)$ \\
The 3rd zones & $20(6.7)$ \\
The 4th zones & $16(5.3)$ \\
The 5th zones & $17(5.7)$ \\
The 6th zones & $33(11.0)$ \\
The 7th zones & $24(8.0)$ \\
The 8th zones & $24(8.0)$ \\
The 9th zones & $14(4.7)$ \\
The 10th zones & $18(6.0)$ \\
The11th zones & $28(9.3)$ \\
The 13th zones & $32(10.7)$ \\
The 15th zones 16 th zones & $17(5.7)$ \\
Unanswered & $14(4.7)$ \\
\hline
\end{tabular}

Note: SD: Standard Division; MMF: Minimum Meal Frequency; MDD: Minimum Dietary Diversity; MAD: Minimum Acceptable Diet; Kg: Kilo gram; Cm: Centimeter; MUAC: Mid Upper Arm Circumference; MAM: Moderate Acute Malnutrition; SAM: Severe Acute Malnutrition; WAZ: Weight for Age Z-score; SD: Standard Division; WLZ: Weight for Length Z-score; LAZ: Length for Age Z-score; CF: Complementary Feeding; Min: Minute 
Table 2: Dietary intakes of children among different age categories

\begin{tabular}{|c|c|c|c|c|}
\hline \multirow[t]{2}{*}{ Variables } & \multicolumn{4}{|l|}{ Age (months) } \\
\hline & All (6-23) & $6-8$ & $9-11$ & $12-23$ \\
\hline Number & 300 & 62 & 90 & 148 \\
\hline Energy (kcal/d) & $341.42 \pm 231.11$ & $215.77 \pm 174.90$ & $287.75 \pm 145.92$ & $426.70 \pm 259.44$ \\
\hline Protein (g/d) & $8.70 \pm 5.76$ & $5.47 \pm 5.03$ & $6.97 \pm 4.21$ & $11.10 \pm 5.86$ \\
\hline Carbohydrate (g/d) & $55.71 \pm 32.67$ & $33.75 \pm 24.55$ & $48.52 \pm 23.79$ & $69.28 \pm 34.03$ \\
\hline Fat (g/d) & $9.69 \pm 16.10$ & $6.66 \pm 7.32$ & $7.69 \pm 5.11$ & $12.19 \pm 21.84$ \\
\hline Vitamin A (RE/d) & $85.05 \pm 106.16$ & $98.53 \pm 144.58$ & $74.79 \pm 94.81$ & $85.64 \pm 93.08$ \\
\hline Vitamin C (mg/d) & $8.68 \pm 9.21$ & $9.62 \pm 14.00$ & $8.36 \pm 7.51$ & $8.47 \pm 7.52$ \\
\hline Vitamin D (Ug/d) & $0.18 \pm 0.34$ & $0.09 \pm 0.28$ & $0.09 \pm 0.18$ & $0.27 \pm 0.40$ \\
\hline Vitamin E (mg/d) & $2.18 \pm 11.17$ & $0.43 \pm 0.61$ & $1.19 \pm 1.10$ & $3.52 \pm 15.79$ \\
\hline Vitamin K (Ug/d) & $6.88 \pm 11.80$ & $1.79 \pm 2.65$ & $5.31 \pm 7.56$ & $9.97 \pm 14.95$ \\
\hline Thiamin B1 (mg/d) & $0.31 \pm 0.20$ & $0.22 \pm 0.22$ & $0.26 \pm 0.16$ & $0.38 \pm 0.20$ \\
\hline Riboflavin B2 (mg/d) & $0.24 \pm 0.22$ & $0.23 \pm 0.31$ & $0.21 \pm 0.18$ & $0.27 \pm 0.20$ \\
\hline NiacinB3 (mg/d) & $2.89 \pm 1.91$ & $1.97 \pm 1.83$ & $2.44 \pm 1.44$ & $3.55 \pm 1.96$ \\
\hline Pyridoxine B6 (mg/d) & $0.22 \pm 0.15$ & $0.13 \pm 0.10$ & $0.21 \pm 0.12$ & $0.27 \pm 0.16$ \\
\hline Folate (Ug/d) & $37.92 \pm 32.73$ & $13.49 \pm 10.99$ & $30.41 \pm 23.07$ & $52.71 \pm 36.05$ \\
\hline Cobalamin B12 (Ug/d) & $0.17 \pm 0.22$ & $0.10 \pm 0.15$ & $0.12 \pm 0.13$ & $0.23 \pm 0.27$ \\
\hline Pant. Acid (mg/d) & $0.56 \pm 0.43$ & $0.26 \pm 0.21$ & $0.46 \pm 0.29$ & $0.74 \pm 0.47$ \\
\hline Biotin (Ug/d) & $1.42 \pm 1.57$ & $0.86 \pm 1.06$ & $1.19 \pm 1.30$ & $1.80 \pm 1.80$ \\
\hline Calcium (mg/d) & $114.40 \pm 109.42$ & $102.24 \pm 138.13$ & $91.17 \pm 88.58$ & $133.61 \pm 104.52$ \\
\hline Chromium (mg/d) & $0.003 \pm 0.007$ & $0.001 \pm 0.002$ & $0.003 \pm 0.003$ & $0.005 \pm 0.009$ \\
\hline Copper (mg/d) & $0.16 \pm 0.11$ & $0.08 \pm 0.08$ & $0.14 \pm 0.07$ & $0.22 \pm 0.12$ \\
\hline Iron (mg/d) & $2.29 \pm 1.68$ & $1.74 \pm 1.98$ & $1.99 \pm 1.26$ & $2.70 \pm 1.67$ \\
\hline Magnesium (mg/d) & $33.85 \pm 23.28$ & $16.57 \pm 13.23$ & $28.79 \pm 17.10$ & $44.16 \pm 24.58$ \\
\hline Manganese (mg/d) & $0.59 \pm 0.44$ & $0.30 \pm 0.25$ & $0.51 \pm 0.32$ & $0.76 \pm 0.49$ \\
\hline Molybdenum (Ug/d) & $1.73 \pm 3.46$ & $0.67 \pm 2.00$ & $0.94 \pm 2.68$ & $2.66 \pm 4.07$ \\
\hline Phosphorus (mg/d) & $167.38 \pm 108.30$ & $119.08 \pm 109.41$ & $150.51 \pm 91.23$ & $197.87 \pm 108.42$ \\
\hline Selenium (mg/d) & $0.002 \pm 0.004$ & $0.001 \pm 0.001$ & $0.001 \pm 0.002$ & $0.004 \pm 0.005$ \\
\hline Zinc (mg/d) & $0.87 \pm 0.60$ & $0.44 \pm 0.33$ & $0.71 \pm 0.44$ & $1.14 \pm 0.63$ \\
\hline Potassium (mg/d) & $306.45 \pm 176.76$ & $192.17 \pm 165.50$ & $270.27 \pm 129.08$ & $376.33 \pm 175.71$ \\
\hline Sodium (mg/d) & $288.11 \pm 285.19$ & $132.74 \pm 127.29$ & $278.91 \pm 286.18$ & $358.79 \pm 306.36$ \\
\hline \multicolumn{5}{|l|}{ Food groups } \\
\hline Red and chicken meat (time/week) & $0.63 \pm 0.75$ & $0.40 \pm 0.57$ & $0.40 \pm 0.59$ & $0.87 \pm 0.84$ \\
\hline Egg (time/week) & $1.00 \pm 1.32$ & $0.46 \pm 0.76$ & $0.67 \pm 0.94$ & $1.41 \pm 1.56$ \\
\hline Fish (time/week) & $0.02 \pm 0.18$ & $0.04 \pm 0.28$ & $0.0001 \pm 0.0001$ & $0.03 \pm 0.18$ \\
\hline Legumes (time/week) & $1.69 \pm 1.41$ & $0.58 \pm 0.75$ & $1.47 \pm 1.20$ & $2.31 \pm 1.44$ \\
\hline Vegetables (time/week) & $1.65 \pm 1.66$ & $0.50 \pm 1.03$ & $1.54 \pm 1.52$ & $2.20 \pm 1.70$ \\
\hline Fruits (time/week) & $2.07 \pm 1.90$ & $1.51 \pm 1.91$ & $1.95 \pm 1.70$ & $2.37 \pm 1.97$ \\
\hline Grains (time/week) & $16.01 \pm 8.20$ & $11.53 \pm 6.38$ & $15.80 \pm 8.32$ & $18.01 \pm 8.10$ \\
\hline Dairy (time/week) & $7.85 \pm 10.16$ & $11.06 \pm 15.48$ & $6.75 \pm 8.78$ & $7.16 \pm 7.63$ \\
\hline Oils (time/week) & $7.10 \pm 4.45$ & $3.48 \pm 3.49$ & $6.26 \pm 4.05$ & $9.12 \pm 3.90$ \\
\hline
\end{tabular}




\begin{tabular}{|lllll|}
\hline Sugar (time/week) & $6.29 \pm 4.59$ & $3.64 \pm 3.24$ & $6.87 \pm 5.12$ & $7.05 \pm 4.34$ \\
\hline Milk Powder (time/week) & $5.78 \pm 10.06$ & $10.08 \pm 14.93$ & $5.27 \pm 8.89$ & $4.28 \pm 7.43$ \\
\hline
\end{tabular}

Data presented as mean and SD: Standard Division

Table 3: Household Food Security and Insecurity of children among different categories of complementary feeding indicators

\begin{tabular}{|c|c|c|c|c|c|c|c|c|c|c|c|c|}
\hline \multirow[t]{2}{*}{ Variables } & \multicolumn{3}{|l|}{ MMF } & \multicolumn{3}{|l|}{ MDD } & \multicolumn{3}{|l|}{ MAD } & \multicolumn{3}{|l|}{ Intro } \\
\hline & Met & Not Met & $\mathrm{P}^{\mathrm{a}}$ & Met & Not Met & $\mathbf{P}^{\mathrm{a}}$ & Good & Poor & $\mathrm{P}^{\mathrm{a}}$ & Yes & No & $\mathrm{P}^{\mathrm{a}}$ \\
\hline Number & 263 & 37 & & 134 & 166 & & 127 & 173 & & 177 & 123 & \\
\hline $\begin{array}{l}\text { Food } \\
\text { secure }\end{array}$ & $27(9.0)$ & $1(0.3)$ & 0.139 & $20(6.7)$ & $8(2.7)$ & 0.003 & 19(6.3) & $9(3.0)$ & 0.004 & $17(5.7)$ & 11(3.7) & 0.846 \\
\hline $\begin{array}{l}\text { Total } \\
\text { food } \\
\text { insecure }\end{array}$ & $236(78.7)$ & $36(12.0)$ & & 114(38.0) & $158(52.7)$ & & 108(36.0) & $164(54.7)$ & & $160(53.3)$ & 112(37.3) & \\
\hline
\end{tabular}

Data are presented as Frequency and percentages (\%)

a $\mathrm{P}$ values presented resulted from analysis of Crosstabs and Chi-Square

MMF: Minimum Meal Frequency; MDD: Minimum Dietary Diversity; MAD: Minimum Acceptable Diet; Intro: Introduction of Complementary Feeding at six months

Table 4: Household Food Security and Insecurity (sub groups) of children among different categories of complementary feeding indicators

\begin{tabular}{|c|c|c|c|c|c|c|c|c|c|c|c|c|}
\hline \multirow[t]{2}{*}{ Variables } & \multicolumn{3}{|l|}{ MMF } & \multicolumn{3}{|l|}{ MDD } & \multicolumn{3}{|l|}{ MAD } & \multicolumn{3}{|l|}{ Intro } \\
\hline & Met & $\begin{array}{l}\text { Not } \\
\text { Met }\end{array}$ & $P^{a}$ & Met & Not Met & $\mathbf{P}^{a}$ & Good & Poor & $P^{a}$ & Yes & No & $P^{a}$ \\
\hline Number & 263 & 37 & & 134 & 166 & & 127 & 173 & & 177 & 123 & \\
\hline Food secure & $27(9.0)$ & $1(0.3)$ & \multirow[t]{4}{*}{0.102} & $20(6.7)$ & $8(2.7)$ & \multirow[t]{4}{*}{0.0001} & $19(6.3)$ & $9(3.0)$ & \multirow[t]{4}{*}{0.0001} & $17(5.7)$ & 11(3.7) & \multirow[t]{4}{*}{0.198} \\
\hline $\begin{array}{l}\text { F.I without } \\
\text { Hunger }\end{array}$ & $98(32.7)$ & $9(3.0)$ & & $58(19.3)$ & $49(16.3)$ & & $57(19.0)$ & $50(16.7)$ & & $69(23.0)$ & $38(12.7)$ & \\
\hline $\begin{array}{l}\text { F.I with } \\
\text { moderate } \\
\text { Hunger }\end{array}$ & 102(34.0) & 21(7.0) & & $43(14.3)$ & $80(26.7)$ & & $40(13.3)$ & $83(27.7)$ & & $72(24.0)$ & $51(17.0)$ & \\
\hline $\begin{array}{l}\text { F.I with Severe } \\
\text { Hunger }\end{array}$ & $36(12.0)$ & $6(2.0)$ & & $13(4.3)$ & 29(9.7) & & 11(3.7) & 31(10.3) & & 19(6.3) & $23(7.7)$ & \\
\hline
\end{tabular}

Data are presented as Frequency and percentages (\%)

a $\mathrm{P}$ values presented resulted from analysis of Crosstabs and Chi-Square

MMF: Minimum Meal Frequency; MDD: Minimum Dietary Diversity; MAD: Minimum Acceptable Diet; Fl: Food Insecurity; Intro: Introduction of Complementary Feeding at six months 
Table 5: Anthropometric measurement among children who start complementary Feeding at 6 months old or not.

\begin{tabular}{|c|c|c|c|}
\hline \multirow[t]{2}{*}{ Variables } & \multicolumn{3}{|c|}{ Start Intro at 6 months } \\
\hline & Yes & No & $\mathbf{P}^{\mathbf{a}}$ \\
\hline Number & 177 & 123 & \\
\hline \multicolumn{4}{|c|}{ Mid Upper Arm Circumference (cm) } \\
\hline$(12.5<)$ Normal & $170(56.7)$ & 106(35.3) & 0.003 \\
\hline (11.5 to $\geq 12.5$ ) MAM & $6(2.0)$ & $17(5.7)$ & \\
\hline$(\geq 11.5)$ SAM & $1(0.3)$ & $0(0)$ & \\
\hline \multicolumn{4}{|l|}{ Weight for Age Z-score (SD) } \\
\hline Good $(-1<,<1$ SD) & 104(34.7) & $54(18.0)$ & 0.001 \\
\hline Partly normal $(-2<,<1)$ & $62(20.7)$ & $44(14.7)$ & \\
\hline Underweight $(-3<,<-2$ SD $)$ & $10(3.3)$ & $20(6.7)$ & \\
\hline Severe underweight $(<-3 \mathrm{SD})$ & $1(0.3)$ & $5(1.7)$ & \\
\hline \multicolumn{4}{|l|}{ Weight for Length Z-score (SD) } \\
\hline Good $(-1<,<1 \mathrm{SD})$ & $125(41.7)$ & $66(22.0)$ & 0.033 \\
\hline Partly normal $(-2<,<1 \mathrm{SD})$ & $43(14.3)$ & $42(14.0)$ & \\
\hline Wasting $(-3<,<-2$ SD $)$ & $6(2.0)$ & $9(3.0)$ & \\
\hline Severe wasting $(<-3 \mathrm{SD})$ & $2(0.7)$ & $4(1.3)$ & \\
\hline Other & $1(0.3)$ & $2(0.7)$ & \\
\hline \multicolumn{4}{|l|}{ Length for Age Z-score (SD) } \\
\hline Good $(-1<,<1$ SD $)$ & $76(25.3)$ & $45(15.0)$ & 0.133 \\
\hline Partly normal $(-2<,<1$ SD $)$ & $63(21.0)$ & $44(14.7)$ & \\
\hline Stunting $(-3<,<-2$ SD $)$ & $25(8.3)$ & $30(10.0)$ & \\
\hline Severe stunting $(<-3 \mathrm{SD})$ & $10(3.3)$ & $3(1.0)$ & \\
\hline Other & $3(1.0)$ & $1(0.3)$ & \\
\hline
\end{tabular}

Data presented as Frequency and Percentage (\%)

a $P$ values presented resulted from analysis of Crosstabs and Chi-Square

MAM: Moderate Acute Malnutrition; SAM: Severe Acute Malnutrition; SD: Standard Division; other: overweight and fat 
Table 6: Anthropometry measurement of children among different complementary feeding indicators

\begin{tabular}{|c|c|c|c|c|c|c|c|c|c|}
\hline \multirow[t]{2}{*}{ Variables } & \multicolumn{3}{|l|}{ MMF } & \multicolumn{3}{|l|}{ MDD } & \multicolumn{3}{|l|}{ MAD } \\
\hline & Met & Not Met & \multirow[t]{2}{*}{$\mathbf{P a}^{\mathbf{a}}$} & Met & Not Met & \multirow[t]{2}{*}{$P^{a}$} & Good & Poor & \multirow[t]{2}{*}{$\mathbf{p}^{\mathbf{a}}$} \\
\hline Number & 263 & 37 & & 134 & 166 & & 127 & 173 & \\
\hline \multicolumn{10}{|c|}{ Mid Upper Arm Circumference (cm) } \\
\hline$(12.5<)$ Normal & $242(80.7)$ & $34(11.3)$ & \multirow[t]{3}{*}{0.927} & $125(41.7)$ & 151(50.3) & \multirow[t]{3}{*}{0.334} & $120(40.0)$ & $156(52.0)$ & \multirow[t]{3}{*}{0.136} \\
\hline$(11.5$ to $\geq 12.5)$ MAM & $20(6.7)$ & $3(1.0)$ & & $8(2.7)$ & $15(5.0)$ & & $6(2.0)$ & $17(5.7)$ & \\
\hline$(\geq 11.5)$ SAM & $1(0.3)$ & $0(0)$ & & $1(0.3)$ & $0(0)$ & & $1(0.3)$ & $0(0)$ & \\
\hline \multicolumn{10}{|l|}{ Weight for Age Z-score (SD) } \\
\hline Good $(-1<,<1 \mathrm{SD})$ & 144(48.0) & $14(4.7)$ & \multirow[t]{4}{*}{0.0001} & $89(29.7)$ & $69(23.0)$ & \multirow[t]{4}{*}{0.0001} & $87(29.0)$ & $71(23.7)$ & \multirow[t]{4}{*}{0.0001} \\
\hline Partly normal $(-2<,<1)$ & $95(31.7)$ & $11(3.7)$ & & $37(12.3)$ & $69(23.0)$ & & $33(11.0)$ & $73(24.3)$ & \\
\hline Underweight $(-3<,<-2$ SD $)$ & $21(7.0)$ & $9(3.0)$ & & $6(2.0)$ & $24(8.0)$ & & $5(1.7)$ & $25(8.3)$ & \\
\hline Severe underweight (<-3 SD) & $3(1.0)$ & $3(1.0)$ & & $2(0.7)$ & $4(1.3)$ & & $2(0.7)$ & $4(1.3)$ & \\
\hline \multicolumn{10}{|l|}{ Weight for Length Z-score (SD) } \\
\hline Good $(-1<,<1 \mathrm{SD})$ & $172(57.3)$ & $19(6.3)$ & \multirow[t]{5}{*}{0.001} & 103(34.3) & $88(29.3)$ & \multirow[t]{5}{*}{0.0001} & $100(33.3)$ & $91(30.3)$ & \multirow[t]{5}{*}{0.0001} \\
\hline Partly normal $(-2<,<1$ SD $)$ & $73(24.3)$ & $12(4.0)$ & & $20(6.7)$ & $65(21.7)$ & & $17(5.7)$ & $68(22.7)$ & \\
\hline Wasting $(-3<,<-2$ SD $)$ & $13(4.3)$ & $2(0.7)$ & & $8(2.7)$ & $7(2.3)$ & & $7(2.3)$ & $8(2.7)$ & \\
\hline Severe wasting (<-3 SD) & $2(0.7)$ & $4(1.3)$ & & $2(0.7)$ & $4(1.3)$ & & $2(0.7)$ & $4(1.3)$ & \\
\hline Other & $3(1.0)$ & $0(0)$ & & $1(0.3)$ & $2(0.7)$ & & $1(0.3)$ & $2(0.7)$ & \\
\hline \multicolumn{10}{|l|}{ Length for Age Z-score (SD) } \\
\hline $\operatorname{Good}(-1<,<1 \mathrm{SD})$ & 113(37.7) & $8(2.7)$ & \multirow[t]{5}{*}{0.0001} & $64(21.3)$ & $57(19.0)$ & \multirow[t]{5}{*}{0.106} & $62(20.7)$ & $59(19.7)$ & \multirow[t]{5}{*}{0.085} \\
\hline Partly normal $(-2<,<1$ SD $)$ & $96(32.0)$ & 11(3.7) & & $45(15.0)$ & $62(20.7)$ & & $42(14.0)$ & $65(21.7)$ & \\
\hline Stunting $(-3<,<-2$ SD $)$ & $43(14.3)$ & $12(4.0)$ & & $21(7.0)$ & $34(11.3)$ & & $19(6.3)$ & $36(12.0)$ & \\
\hline Severe stunting $(<-3 \mathrm{SD})$ & $10(3.3)$ & $3(1.0)$ & & $3(1.0)$ & $10(3.3)$ & & $3(1.0)$ & $10(3.3)$ & \\
\hline Other & $1(0.3)$ & $3(1.0)$ & & $1(0.3)$ & $3(1.0)$ & & $1(0.3)$ & $3(1.0)$ & \\
\hline
\end{tabular}

Data are presented as Frequency and Percentage (\%)

a $P$ values presented resulted from analysis of Crosstabs and Chi-Square;

MMF: Minimum Meal Frequency; MDD: Minimum Dietary Diversity; MAD: Minimum Acceptable Diet; MAM: Moderate Acute Malnutrition; SAM: Severe Acute Malnutrition; SD: Standard Division

Table 7: Odds ratios and 95\% confidence intervals for low MUAC, Underweight, Wasting and Stunting among those who did not meet the complementary feeding criteria.

\begin{tabular}{|c|c|c|c|c|c|c|c|c|}
\hline \multirow[t]{2}{*}{ Variable } & \multirow{2}{*}{$\begin{array}{l}\text { MMF } \\
\text { OR }(95 \% \mathrm{Cl})\end{array}$} & \multirow{2}{*}{$\begin{array}{l}P \\
\text { Value }\end{array}$} & \multirow{2}{*}{$\begin{array}{l}\text { MDD } \\
\text { OR (95\%Cl) }\end{array}$} & \multirow{2}{*}{$\begin{array}{l}\mathrm{P} \\
\text { Value }\end{array}$} & \multirow{2}{*}{$\begin{array}{l}\text { MAD } \\
\text { OR }(95 \% \mathrm{Cl})\end{array}$} & \multirow{2}{*}{$\begin{array}{l}\mathrm{P} \\
\text { Value }\end{array}$} & \multirow{2}{*}{$\begin{array}{l}\text { Intro } \\
\text { OR }(95 \% \mathrm{Cl})\end{array}$} & \multirow{2}{*}{$\begin{array}{l}P \\
\text { Value }\end{array}$} \\
\hline & & & & & & & & \\
\hline Mid Upper Arm Circumference & $1.01(0.28-3.59)$ & 0.979 & $1.38(0.58-3.25)$ & 0.463 & $1.86(0.75-4.64)$ & 0.179 & $0.25(0.10-0.64)$ & 0.004 \\
\hline Weight for Age Z-score & $1.98(0.98-4.03)$ & 0.057 & $2.78(1.73-4.46)$ & 0.0001 & $3.12(1.93-5.05)$ & 0.0001 & $0.54(0.34-0.87)$ & 0.012 \\
\hline Weight for Length Z-score & $1.79(0.89-3.58)$ & 0.099 & $2.94(1.77-4.87)$ & 0.0001 & $3.33(1.98-5.61)$ & 0.0001 & $0.48(0.29-0.77)$ & 0.003 \\
\hline Length for Age Z-score & $2.73(1.20-6.20)$ & 0.016 & $1.74(1.09-2.78)$ & 0.019 & $1.84(1.15-2.94)$ & 0.011 & $0.76(0.47-1.23)$ & 0.270 \\
\hline
\end{tabular}

a $P$ values were calculated using logistic regression.

MMF: Minimum Meal Frequency; MDD: Minimum Dietary Diversity; MAD: Minimum Acceptable Diet; Intro: Introduction of complementary feeding at six months of child; OR: Odds Ratio; Cl: Confidence Interval 
Table 8: Odds ratios and 95\% confidence intervals for low MUAC, Underweight, Wasting and Stunting among classification of food insecurity.

\begin{tabular}{|lll|}
\hline Variable & Classification of food security & P \\
\cline { 2 - 3 } & OR $(95 \% \mathrm{Cl})$ & Value \\
\hline Mid Upper Arm Circumference & $2.49(0.32-19.20)$ & 0.380 \\
\hline Weight for Age Z-score & $3.66(1.44-9.32)$ & 0.006 \\
\hline Weight for Length Z-score & $8.43(1.96-36.25)$ & 0.004 \\
\hline Length for Age Z-score & $5.16(2.11-12.56)$ & 0.0001 \\
\hline
\end{tabular}

$P$ values were calculated using logistic regression.

Classification of food security are including: Food secure, Food insecure without hunger, Food insecure with moderate hunger and Food insecure with severe hunger

OR: Odds Ratio; Cl: Confidence Interval

\section{Figures}

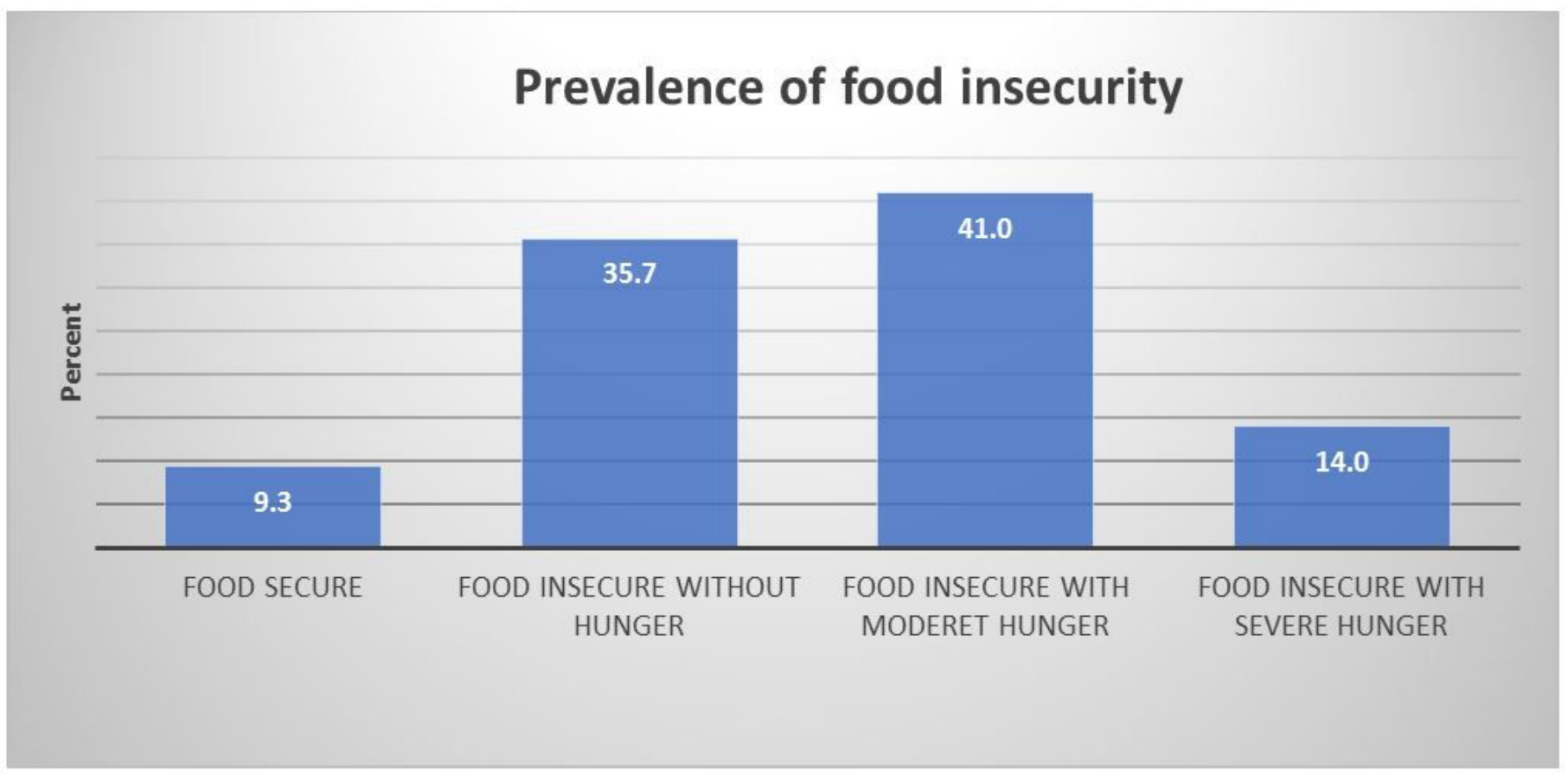

Figure 1

Prevalence of household food insecurity 


\section{Complementary feeding practice indicators}

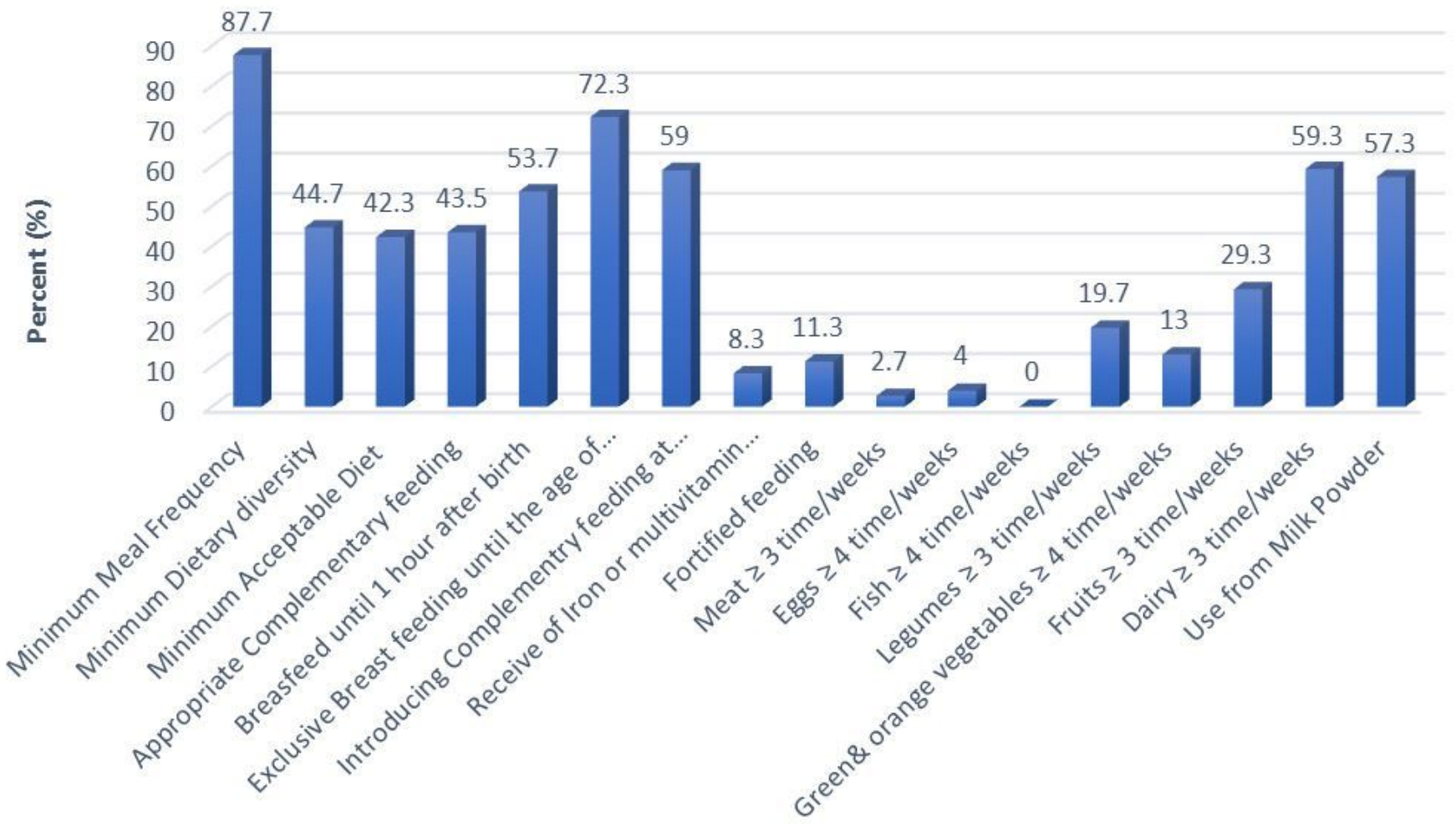

Figure 2

Complementary feeding practice indicators among children aged 6-23 months

\section{Supplementary Files}

This is a list of supplementary files associated with this preprint. Click to download.

- CoverLetter.doc

- ReferencePDF.pdf 